ИННОВАЦИОННЫЕ РАЗРАБОТКИ ДЛЯ ПРОФИЛАКТИКИ ЭКОНОМИЧЕСКИ ЗНАЧИМЫХ БОЛЕЗНЕЙ ВЫСОКОПРОДУКТИВНЫХ ЖИВОТНЫХ В ПРОМЫШЛЕННОМ ЖИВОТНОВОДСТВЕ

\author{
ЕВГЛЕВСКАЯ Е.П., \\ кандидат сельскохозяйственных наук, доцент ФГБОУ ВО Курская ГСХА.
}

ЕВГЛЕВСКИЙ Ал.А., доктор ветеринарных наук, профессор, главный научный сотрудник Курского Федерального аграрного научного центра, заведующий лабораторией «Ветеринарная медицина».

Реферат. В статье представлен краткий анализ состояния молочного животноводства и проект авторских предложений по решению проблем в части обеспечения здоровья высокопродуктивных животных. Научные разработки, представленные в данной статье, выполнены при активном участии доцента Курской ГСХА Евглевской Елены Павловны. Она автор целого ряда научных направлений в области инфекционной и незаразной патологии. В данном сообщении инновационные разработки представлены серией оригинальных по составу и лечебно-профилактическому действию энергометаболических композиций и методологии их применения, позволяющих при минимальных экономических и экологических издержках обеспечить высокие показатели здоровья высокопродуктивных коров в прогнозируемые периоды риска развития патобиохимических процессов и патофизиологических состояний, в частности, коррекции метаболизма и профилактики энергодефицитных состояний у глубокостельных и новотельных коров; профилактики ацидоза рубца, метаболического кетоацидоза, гепатозов в лактационный период; профилактики гипомикроэлементозов и йодной недостаточности; профилактики заболеваний дистального отдела конечностей; профилактики и лечению желудочно-кишечных и респираторных заболеваний, иммунодефицитов и нарушений обменных процессов у телят и молодняка.

Ключевые слова: высокопродуктивные коровы, ацидоз рубца, метаболический ацидоз, метаболический кетоацидоз, гепатозы, гипомикроэлементозы, йодная недостаточность, энергодефицитные состояния, энергометаболические составы.

\title{
INNOVATIVE DEVELOPMENTS FOR THE PREVENTION OF ECONOMICALLY IMPORTANT DISEASES OF HIGHLY PRODUCTIVE ANIMALS IN INDUSTRIAL FARMING
}

EVGLEVSKAYA E.P.,

candidate of agricultural Sciences, associate Professor of Kursk gsha

\section{EVGLEVSKY Al. A.,}

doctor of veterinary Sciences, Professor, chief researcher of the Kursk Federal agrarian scientific center, head of the laboratory "Veterinary medicine".

Essay. The article presents a brief analysis of the state of dairy farming and the draft author's proposals to address the problems in terms of ensuring the health of highly productive animals. Scientific developments presented in this project were carried out with the active participation of associate Professor of Kursk state agricultural Academy Elena Pavlovna. She is the author of a number of scientific directions in the field of infectious and non-infectious pathology. In this report, innovative developments are presented to a series of original composition and therapeutic and preventive action of energy-metabolic compositions and methodology of their application, allowing at minimal economic and environmental costs to ensure high health indicators of highly productive cows in the predicted periods of risk of development of pathobiochemical processes and pathophysiological conditions, in particular, the correction of metabolism and prevention of energy-deficient conditions in deep-bed cows and new-bodied cows; - prophylaxis of rumen acidosis, metabolic ketoacidosis, hepatosis in the lactic period; - prevention of hypomicroelementosis and iodine deficiency;-prevention of diseases of the distal extremities; - prevention 


\section{ДИАГНОСТИКА БОЛЕЗНЕЙ И ТЕРАПИЯ ЖИВОТНЫХ, ПАТОЛОГИЯ, ОНКОЛОГИЯ И МОРФОЛОГИЯ ЖИВОТНЫХ}

and treatment of gastrointestinal and respiratory diseases, immunodeficiency and metabolic disorders in calves and young animals.

Key words: highly productive cows, rumen acidosis, meta-Bolic acidosis, metabolic ketoacidosis, hepatoses, hypomicroelements, iodine deficiency, energy-deficient States, energy-metabolic compositions.

Введение. В ряду экономически значимых проблем развития отечественного животноводства ключевую роль имеют вопросы обеспечения здоровья высокопродуктивных коров. Эйфория относительно того, что импортные технологии и высокопродуктивный скот зарубежной селекции, это наиболее быстрое и эффективное решение проблемы развития отечественного животноводства в реалиях производства сдерживаются крайне высокими показателями преждевременного выбытия животных. Средние показатели эксплуатации высокопродуктивных коров на молочных комплексах страны с трудом преодолевают две лактации. Выход телят на 100 коров редко достигает $70 \%$. Эти показатели не только не могут обеспечить воспроизводство и сохранение генетического потенциала высокопродуктивных коров, но и экономическую рентабельность молочных комплексов. К примеру, в Курской области уже ряд молочных комплексов, еще недавно укомплектованных импортным поголовьем животных, прекратили свою производственную деятельность. Развитие такой ситуации вполне закономерный итог за отсутствие знаний и опыта работы с высокопродуктивными животными. Принимая во внимание экономическую ситуацию в стране, возможности закупить по импорту скот крайне ограничены. В этой связи, наши научные разработки вполне могут качественно улучшить экономическую рентабельность молочного животноводства. Они доказали свою эффективность в самых сложных, а порой в критических ситуациях, подобно той какая сложилась в 2014 г. на молочном комплексе «Благодатенский». Как известно, в условиях современного промышленного животноводства основное выбытие высокопродуктивных коров идет по причине метаболических болезней [111]. Патологии метаболического генеза обусловили массовый и повсеместный характер заболеваний коров метаболическим ацидозом, кетозом, гепатозом, остеомаляцией, остеодистрофией. Для многих хозяйств, трудноразрешимыми вопросами стали: родовые патологии, задержание последа, эндометриты, заболевания дистального отдела конечностей, суставные патологии. Патобиохимические процессы у глубокостельных и новотельных коров достигают критических значений. В этой связи, большинство высокопродуктивных коров выбраковываются сразу после отела или в первый месяц лактации [1, 3-7].

Для коррекции патобиохимических процессов, профилактики пат физиологических и иммунодефицитных состояний зарубежные фирмы предлагают и массово реализуют весьма дорогостоящие б опрепараты и биологически активные добавки. По сути, запущен мощный прессинг импортных биопрепаратов. Совершенно, очевидно, что в нынешних экономических реалиях многие из импортных препаратов и биологически активных добавок стали недоступными для большинства хозяйств. К примеру, разовая доза любого импортного энергетика более 1000 рублей, что в десятки раз дороже пищевого сахара. Отечественных энергетических добавок практически нет (Обзор российского рынка энергетических кормовых добавок. Интернет источник: Soyanew 26.01.2015). В этой связи требуется качественно иной подход к проблеме обеспечения здоровья продуктивных животных, в том числе и в части, реального замещения импортных биологически активных препаратов и энергетических добавок. Именно это обстоятельство было принято во внимание и послужило основанием для разработки средств энергометаболической направленности из экономически доступных, экологически безопасных и хорошо известных компонентов.

Цель исследований. Разработка средств энергометаболической направленности, обеспечивающих эффективную коррекцию патобиохимических процессов, профилактику экономически значимых болезней высокопродуктивных коров и молодняка в промышленном животноводстве. Исходя из цели, необходимо решить следующие задачи:

- профилактика патобиохимических процессов и энергодефицитных состояний у глубокостельных и новотельных коров;

- профилактика ацидоза рубца, метаболического кетоацидоза, гепатозов в лактационный период;

- профилактика гипомикроэлементозов и йодной недостаточности; 
- профилактика заболеваний дистального отдела конечностей;

-профилактика и лечение желудочнокишечных и респираторных заболеваний, иммунодефицитов и нарушений обменных процессов у телят и молодняка.

Результаты исследования. В настоящее время, в условиях промышленного животноводства, прошли и проходят клинические испытания инновационные разработки средств энергометаболической направленности. Эти средства представляют собой биологически активные комплексы, проявляющие клинически выраженный позитивный эффект при наиболее распространенных, экономически значимых метаболических болезнях и патофизиологических состояниях у коров и молодняка. Их применение показано для профилактики и лечения ацидоза рубца, метаболического ацидоза, кетоза, кормовых микотоксикозов, гепатозов, гипомикроэлементозов, обеспечения благоприятного течения родов, усиления ростовой активности и профилактики желудочно-кишечных заболеваний с диарейным синдромом. Какие проблемные задачи они позволяют решить при минимальных экономических издержках?

Во-первых, профилактика энергодефицитных состояний при родах и в ранний лактационный период. В чем проблема? В настоящее время наиболее уязвимой категорией животных являются глубокостельные и новотельные коровы. Патобиохимические процессы у них достигают критических значений. В этой связи, большинство высокопродуктивных коров выбраковываются сразу после отела или в первый месяц лактации. Ведущей причиной является дефицит энергии $[4,11]$. Дефицит энергии чаще всего связан с недостатком в рационе легкоусвояемых углеводов (сахаров). Недостаток энергии в организме является причиной тяжелых родов, задержания последа, и как следствие заболевания эндометритом. Особенно остро проблема дефицита энергии отразилась при растелах новотельных импортных коров. Дефицит энергии далее отражается на послеродовой реабилитации репродуктивной системы. Решению данной проблемы предназначен состав для стимуляции энергометаболических процессов, профилактики родовых патологий и послеродовых заболеваний (Патент РФ № 2553360 от 10.06. 2015). Разработка успешно апробирована на целом ряде молочных комплексов Курской области

Во-вторых, профилактика ацидоза рубца, кетоацидоза, гепатозов в лактационный период. В чем проблема? В современном молочном животноводстве проблема ацидоза рубца, кетоацидоза, гепатозов у коров является наиболее экономически значимой [2-11]. Это связано с тем, что никакими кормовыми факторами не удается преодолеть дефицит физиологически полезной энергии новотельных высокопродуктивных коров. Более того, включение в рацион высококалорийных концентратов порождает проблему синтеза значительных объемов молочной кислоты из крахмала концентратов. Принимая во внимание, что на современных молочных комплексах коровам круглый год скармливают в больших количествах кислые консервированные корма (силос, сенаж), вполне естественно происходит закисление рубца (ацидоз рубца). При развитии острого закисления рубца (ацидоз) резко снижается аппетит и поедаемость корма. С проявлением голодного сигнала происходит активное вовлечение в энергетический обмен жировых запасов собственного тела. Опасность состоит в том, что организм высокоудойных коров может использовать большое количество жиров - до 60 кг. При столь интенсивном вовлечении жиров в энергетические процессы печень не может справиться с их использованием. С повышением жировой инфильтрации печень последняя фактически утрачивает метаболическую и дезинтоксикационную функцию. Решению проблемы рубцового пишеварения и нормализации патобиохимических процессов при метаболическом ацидозе, кетоацидозе и жировом гепатозе предназначены: энергометаболический состав для нормализации биохимических процессов при алиментарных ацидозах, гепатозах и микотоксикозах укоров (Патент РФ № 2563237 от 20.09.2015); энергометаболической состав для профилактики и лечения кетоза и гепатоза у коров (Патент РФ № 2645769 от 28.02.2018) и энергометаболический состав для профилактики и лечения ацидоза рубца, метаболического ацидоза у новотельных коров (Патент РФ №2650640 от 16.04.2018). Разработки успешно испытаны на целом ряде молочных комплексов (МК) Курской области

В-третьих, профилактика кормовых микотоксикозов. В чем проблема? Серьезной проблемой животноводства России являются кормовые микотоксикозы $[9,10]$. В реальных производственных условиях чаще всего регистрируются поражения кормов несколькими видами микотоксинов. Токсигенные плесневые грибы и их метаболиты, поражая корма, вызывают острую и хроническую интоксикацию ор- 
ганизма животных. Они являются одной из ведущих причин заболеваний печени (гепатозы). Даже самые малые их количества оказывают неблагоприятное влияние на метаболические процессы и систему иммунитета. Принимая во внимание, что абсолютно чистых кормов нет и реально нет возможности исключить такие корма из рациона перед ветеринарной наукой и практикой стоит весьма проблемная задача каким образом снизить вред от микотоксинов. В настоящее время наиболее изученным и достаточно эффективным методом снижения негативного действия микотоксинов является применение энтеросорбентов. Однако, применение адсорбентов не дает быстрого позитивного результата. Вполне закономерно возникает сомнение в их эффективности. Кроме того, что адсорбенты выводят из пищеварительного тракта жизненно важные микроэлементы. При длительном применении они способствуют развитию гипомикроэлементозов. По нашему мнению перспективным направлением профилактики и лечения кормовых микотоксикозов, особенно в части острого клинического течения, может быть создание комплексных препаратов, кормовых добавок, обеспечивающих эффективную детоксикацию организма и нормализацию работы пораженных токсинами органов, в первую очередь печени. В качестве средств интенсивной дезинтоксикации и нормализации патобиохимических процессов при кормових микотоксикозах разработан и с высокой эффективностью прошел клинические испытания в условиях крупного молочного комплекса «Благодатенский» энергометаболический состав для нормализации биохимических процессов при алиментарных ацидозах, гепатозах и микотоксикозах у коров (Патент РФ № 2563237 от 20.09.2015).

В-четвертых, профилактика гипомикроэлементозов и йодной недостаточности. В чем проблема? Проблема гипомикроэлементозов обусловлена низким (до $30 \%$ от нормы) содержанием в растительных кормах жизненно важных микроэлементов на всей территории
Российской Федерации. В ряду гипомикроэлементозов особое место занимает йодная недостаточность. При дефиците йода щитовидная железа не способна полноценно выполнять функцию защиты организма от инфекционных патогенов. При йодной недостаточности невозможно защитить организм от возбудителей инфекций. Не помогут ни вакцины, ни самые сильные антибиотики. Для профилактики гипомикроэлементозов и йодной недостаточности разработаны и прошли клинические испытания в целом ряде хозяйств Курской и Ростовской областей комплексные энергометаболические композиции на основе органических кислот и жизненно важных микроэлементов. Патент РФ № 2620557 от 26.05.2017 Энергометаболический состав для превентивной терапии метаболического ацидоза, кетоза и йодной недостаточности у коров (Патент РФ № 2620557 от 26.05.2017) и способ профилактики йодной недостаточности и коррекции метаболизма у коров (Патент РФ № 2664438 от 17.08.2018). Разработки успешно апробированы в целом ряде хозяйств Курской и Ростовской областей.

Таким образом, представленные в данном проекте разработки охватывают наиболее проблемные задачи по сохранению здоровья высокопродуктивных коров и молодняка в промышленном животноводстве.

Вывод. Для профилактики экономически значимых болезней животных в промышленном животноводстве осуществлена разработка целой серии средств энергометаболической направленности. Высокая эффективность доказана в самых сложных клинических случаях, в том числе, когда известные разработки западных фирм оказались несостоятельными. Технологическая простота получения, доступность и экологическая безопасность компонентов позволяют готовить некоторые из них даже в условиях ферм. В нынешних условиях это реальная перспектива альтернативы импортным средствам энергометаболической направленности.

\section{Список использованных источников}

1. Основные причины выбытия высокопродуктивных коров / В.А. Мищенко и др. // Ветеринария. - 2004. - № 4. - С. 15-17.

2. Анализ нарушения обмена веществ у высокоудойных коров / В.А. Мищенко и др. // Ветеринария Кубани. - 2012. - № 6.

3. Проблема сохранности высокопродуктивных коров / В.А. Мищенко, Н.А. Яременко, Д.К. Павлов, А.В. Мищенко // Ветеринарная патология.- 2005. - № 3. - С. 95-99.

4. Измайлов Е. Энергетический кризис или куда ведет дефицит сахаров // Нивы Зауралья. 2014. - № 6. 
5. Евглевский Ал. А., Турнаев С.Н. Причины выбытия коров на молочных комплексах Курской области: состояние, проблемы, пути решения // Вестник Курской государственной сельскохозяйственной академии. - 2014. - № 9. - С. 67-69.

6. Проблемы обеспечения здоровья высокопродуктивных коров в промышленном животноводстве и практические пути ее решения / Ал.А. Евглевский, С.Н. Турнаев, В.Ю. Тарасов и др. // Вестник Курской государственной сельскохозяйственной академии. - 2017. - № 4. - С. 26-30.

7. Евглевский А.А. и др. Патобиохимические изменения в метаболическом статусе высокопродуктивных коров // Ветеринарная патология. - 2016. - № 1. - С. 75-80.

8. Нарушение кислотно-основного состояния в организме коров: причины, последствия, пути решения / Ал.А. Евглевский, Е.П. Евглевская, И.И. Михайлова и др. // Ветеринарная патология. 2017. - № 1 (59).- С. 53-56.

9. Метаболический ацидоз у высокопродуктивных коров: причины, последствия, профилактика / А.А. Евглевский, В.Н. Скира, Е.П. Евглевская и др. // Ветеринария. - 2017. - № 5. - С. 45-48.

10. Метаболический кетоацидоз высокопродуктивных лактирующих коров: причины, последствия и перспективные подходы решения / Ал.А. Евглевский, О.М. Швец, Е.П. Евглевская и др. // Вестник Курской государственной сельскохозяйственной академии. - 2018. - № 2. - С. 27-30.

11. Дефицит энергии у новотельных коров: проблемы и решения / А.А. Евглевский, Н.Ф. Ерыженская, В.Н. Скира и др. // Вестник Российской сельскохозяйственной науки. - 2017. - С. 43.

12. Кормовые микотоксикозы коров в промышленном животноводстве: причины, последствия и эффективные подходы профилактики и лечения / А.А. Евглевский, Е.П. Евглевская, И.И. Михайлова и др. // Ветеринарная патология. - 2018. - № 1 (63). - С. 47-53.

13. Эффективность применения энергометаболического состава на основе органических кислот при кормовом микотоксикозе коров / А.А. Евглевский, В.Н. Скира, С.Н. Турнаев и др. // Ветеринария. - № 10. - С. 44-47.

\section{List of used sources}

1. The main reasons for the retirement of highly productive cows / V.A. Mishchenko et al. // Veterinary. - 2004. - № 4. - P. 15-17. - № 6 .

2. Analysis of metabolic disorders in high-cows / V.A. Mi-shchenko, etc. // Veterinary Kuban. - 2012.

3. The problem of the preservation of highly productive cows / V.A. Mishchenko, N.A. Yaremenko, D.K. Pavlov, A.V. Mishchenko // Veterinary Pathology. - 2005. - № 3. - P. 95-99.

4. Izmailov E. Energy crisis or where sugar deficiency leads // Niva Zauralye. - 2014. - № 6.

5. Evglevsky Al. A., Turnaev S.N. Causes of cows leaving the dairy complexes of the Kursk region: state, problems, solutions // Bulletin of the Kursk State Agricultural Academy. - 2014. - № 9. - P. 67-69.

6. Problems of ensuring the health of highly productive cows in industrial animal husbandry and practical ways to solve it / Al.A. Evglevsky, S.N. Turnaev, V.Yu. Tarasov et al. // Bulletin of the Kursk State Agricultural Academy. - 2017. - № 4. - P. 26-30.

7. Evglevsky A.A. Pathobiochemical changes in the metabolic status of highly productive cows // Veterinary pathology. - 2016. - № 1. - P. 75-80.

8. Violation of the acid-base state in the body of cows: causes, consequences, solutions / Al.A. Evglevsky, E.P. Evglevskaya, I.I. Mikhailova et al. // Veterinary Pathology. - 2017. - № 1 (59). - P. 53-56.

9. Metabolic acidosis in highly productive cows: causes, consequences, prevention / A.A. Evglevsky, V.N. Skira, E.P. Evglevskaya and others // Veterinary medicine. - 2017. - № 5. - P. 45-48.

10. Metabolic ketoacidosis of highly productive lactating cows: causes, consequences and promising approaches of the solution / Al.A. Evglevsky, O.M. Shvets, E.P. Evglevskaya and others // Bulletin of the Kursk State Agricultural Academy. - 2018. - № 2. - P. 27-30.

11. Energy deficiency in fresh cows: problems and solutions / A.A. Evglevsky, N.F. Eryzhenskaya, V.N. Skira and others // Bulletin of the Russian agricultural science. - 2017. - P. 43.

12. Fodder mycotoxicosis of cows in industrial animal husbandry: causes, consequences and effective approaches of prevention and treatment / A.A. Evglevsky, E.P. Evglevskaya, I.I. Mikhailova et al. // Veterinary Pathology. - 2018. - № 1 (63). - Pp. 47-53.

13. Efficiency of using an energy-metabolic composition based on organic acids in cows mycotoxicosis / A.A. Evglevsky, V.N. Skira, S.N. Turnaev et al. // Veterinary medicine. - № 10. - P. 44-47. 